\title{
Identifikasi Vektor Malaria di Daerah Sekitar PLTU Teluk Sirih Kecamatan Bungus Kota Padang Pada Tahun 2011
}

\author{
Rezka Gustya Sari ${ }^{1}$, Nurhayati ${ }^{2}$, Rosfita Rasyid $^{3}$
}

\begin{abstract}
Abstrak
Malaria adalah penyakit infeksi parasit yang disebabkan oleh protozoa obligat intraselular dari genus Plasmodium yang ditularkan nyamuk Anopheles. Bungus merupakan salah satu kecamatan dengan kasus malaria tinggi di Kota Padang, terdapat 69 kasus malaria pada tahun 2011. Pengendalian vektor malaria dibutuhkan pengetahuan mengenai spesies vector. Tujuan penelitian ini adalah menentukan spesies nyamuk tersangka vektor malaria. Penelitian dilaksanakan dari Oktober sampai November 2011. Nyamuk Anopheles di tangkap di dalam dan di luar ruangan menggunakan light trap dan umpan orang menggunakan aspirator. Penangkapan dilakukan pada malam hari pada jam 18.00 - 06.00 dan pagi hari pada jam 07.00 - 09.00. Semua nyamuk yang berhasil tertangkap diidentifikasi di bawah mikroskop. Bedasarkan penelitian yang telah dilakukan didapatkan nyamuk An.subpictus, An.sundaicus dan An.aconitus dengan persentase (49,5\%), (29,4\%) dan (14,7\%). Hal ini menunjukkan bahwa An.sundaicus, An.subpictus dan An.aconitus memiliki potensi yang besar dalam penularan penyakit malaria.
\end{abstract}

Kata kunci: malaria, vektor malaria

\begin{abstract}
Malaria is a disease caused by intracellular obligate protozoa, genus of plasmodium which is a parasite is carried by Anopheles mosquito. Bungus subdistrict is one of the areas that has high case of malaria in Padang district of Sumatera Barat Province, there were 69 case of malaria. Determination of method of control requires an understanding on the species of mosquito which serves as the vector and its behavior. The objective of this study was to assess fauna and the activity of Anopheles spp as suspected malaria vector. This research had done on October to November 2011. The Anopheles mosquitoes were collected indoor and outdoor by using light trap and human landing collection in the evening starting from 6 p.m - 6 a.m, in the morning from 7 - 9 a.m. All the Moquitoes were brougt to the laboratory for identifications. The resut showed that An. subpictus (49.5\%) An. sundaicus (29.4\%) and A. aconitus (14.7\%). were the suspected malaria vector that has important role in tranmission of malaria in this area.
\end{abstract}

Keywords: malaria, malaria vektor

Affiliasi penulis: 1. Prodi Profesi Dokter FK UNAND (Fakultas Kedokteran Universitas Andalas Padang), 2. Bagian Parasitologi FK UNAND, 3. Bagian IImu Kesehatan Masyarakat FK UNAND.

Korespondensi: Rezka Gustya Sari, Email:

rezka_crezz@yahoo.co.id, Telp: +628990222624

\section{PENDAHULUAN}

Malaria adalah penyakit infeksi parasit yang disebabkan oleh protozoa obligat intraselular dari genus Plasmodium. ${ }^{1}$ Malaria adalah penyebab ke-5 terbesar dari kematian akibat infeksi di seluruh dunia, dengan kasus malaria baru 200-300 juta/tahun. Satu juta penduduk dunia meninggal tiap tahunnya disebabkan oleh malaria. ${ }^{2} \mathrm{Di}$ Indonesia penyakit malaria di temukan terbesar di seluruh kepulauan. Indonesia memiliki $484 \mathrm{Kab} / \mathrm{Kota}, 338$ diantaranya merupakan wilayah endemis malaria. ${ }^{3}$

Pengetahuan mengenai spesies vektor malaria pada suatu daerah sangat penting sebagai dasar pertimbangan untuk menentukan intervensi dalam pengendalian vektor yang lebih efektif. ${ }^{4}$ 
Penelitian ini bertujuan untuk mengetahui jenis nyamuk Anopheles yang berpotensi sebagai tersangka vektor malaria di daerah sekitar PLTU Teluk Sirih Kecamatan Bungus Kota Padang pada tahun 2011.

\section{METODE}

Penelitian bersifat survey deskriptif, data diolah dengan menggunakan rumus kepadatan relatif nyamuk yaitu Man bitting Rate (MBR) dan Man Hours Density (MHD).

Survey dilakukan dari Oktober sampai November 2011, di daerah sekitar PLTU Teluk Sirih Kecamatan Bungus Kota Padang. Semua nyamuk Anopheles yang berhasil tertangkap di identifikasi di laboratorium Parasitologi Fakultas Kedokteran Universitas Andalas.

Pengumpulan sampel dilakukan di lapangan dan di laboratorium. Di lapangan menggunakan alat light trap dan aspirator, di laboratorium menggunakan mikroskop dissection.

Pertama, koleksi nyamuk dilakukan dengan dua cara: light trap dan Umpan orang. Light Trap, dipasang pada malam hari di dalam dan di luar rumah pada pukul 18.00 dan diambil pada pukul 06.00. Umpan orang dilakukan oleh 2 orang untuk di dalam dan di luar rumah.

Kedua, nyamuk hasil tangkapan light trap dan aspirator di letakkan pada ujung kertas dan di tempel dengan kutek bening, kemudian di Identifikasi di bawah mikroskop dissection spesies dari nyamuk tersebut.

HASIL

Tabel 1. Anopheles yang tertangkap selama penelitian di daerah sekitar PLTU Teluk Sirih Kecamatan Bungus

\begin{tabular}{|c|c|c|c|c|}
\hline \multicolumn{2}{|c|}{ Light trap } & \multicolumn{2}{|c|}{ Umpan orang } & \multirow{2}{*}{$\begin{array}{c}\text { Jumlah } \\
\text { (ekor) }\end{array}$} \\
\hline LR & DR & LR & $\overline{D R}$ & \\
\hline (ekor) & (ekor) & (ekor) & (ekor) & \\
\hline 38 & 71 & 45 & 18 & 177 \\
\hline
\end{tabular}

*LR: Luar Rumah

*DR: Dalam Rumah
Tabel 2. Anopheles yang tertangkap dengan light trap bedasarkan spesies dan lokasi penangkapan

\begin{tabular}{|c|c|c|c|c|c|}
\hline & \multicolumn{5}{|c|}{ Spesies Anopheles } \\
\hline & $\begin{array}{c}\text { An. } \\
\text { subpictus }\end{array}$ & $\begin{array}{c}\text { An. } \\
\text { aconitus }\end{array}$ & $\begin{array}{c}\text { An. } \\
\text { kochi }\end{array}$ & $\begin{array}{c}\text { An. } \\
\text { sundaicus }\end{array}$ & $\begin{array}{c}\text { An. } \\
\text { barbitoris }\end{array}$ \\
\hline DR & 18 & 5 & 0 & 12 & 3 \\
\hline $\mathrm{LR}^{*}$ & 36 & 11 & 2 & 20 & 2 \\
\hline Jmh & $\begin{array}{c}54 \\
(49,5 \%)\end{array}$ & $\begin{array}{c}16 \\
(14,7 \%)\end{array}$ & $\begin{array}{c}2 \\
(1,8 \%)\end{array}$ & $\begin{array}{c}32 \\
(29,4 \%)\end{array}$ & $\begin{array}{c}5 \\
(4,65 \%)\end{array}$ \\
\hline
\end{tabular}

*DR: Dalam Rumah

*LR: Luar Rumah

Tabel 3. Nyamuk Anopheles yang tertangkap dengan umpan orang malam hari berdasarkan spesies dan lokasi penangkapan

\begin{tabular}{cccc}
\hline Lokasi & \multicolumn{3}{c}{ Spesies Anopheles } \\
\cline { 2 - 4 } & $\begin{array}{c}\text { An. } \\
\text { aconitus }\end{array}$ & $\begin{array}{c}\text { An. } \\
\text { sundaicus }\end{array}$ & $\begin{array}{c}\text { An. } \\
\text { subpictus }\end{array}$ \\
\hline DR & 3 & 6 & 9 \\
LR $^{*}$ & 8 & 10 & 27 \\
\hline Jumlah & 11 & 16 & 36 \\
& $(17,5 \%)$ & $(25,4 \%)$ & $(57,1 \%)$ \\
\hline
\end{tabular}

*DR: Dalam Rumah

*LR: Luar Rumah

Tabel 4. Nyamuk Anopheles yang tertangkap dengan umpan orang pagi hari bedasarkan spesies dan lokasi penangkapan

\begin{tabular}{lccc}
\hline Lokasi & \multicolumn{3}{c}{ Spesies Anopheles } \\
\cline { 2 - 4 } & $\begin{array}{c}\text { An. } \\
\text { aconitus }\end{array}$ & $\begin{array}{c}\text { An. } \\
\text { sundaicus }\end{array}$ & $\begin{array}{c}\text { An. } \\
\text { subpictus }\end{array}$ \\
\hline DR & 0 & 0 & 2 \\
LR $^{*}$ & 3 & 0 & 0 \\
\hline Jumlah An. Spp & 3 & 0 & 2 \\
*DR: Dalam Rumah & & & \\
*LR: Luar Rumah & &
\end{tabular}


Tabel 5. Kepadatan Relatif Nyamuk Anopheles yang tertangkap dengan umpan orang pada malam hari

\begin{tabular}{clccc}
\hline $\begin{array}{c}\text { Tanggal } \\
\text { penang } \\
\text { kapan }\end{array}$ & $\begin{array}{l}\text { Lokasi } \\
\text { Penang }\end{array}$ & \multicolumn{3}{c}{ Spesies Anopheles } \\
\cline { 3 - 5 } & An. & An. & An. \\
subpictus & sundaicus & sconitus \\
(MBR) & (MBR) & (MBR) \\
\hline $8 / 10 / 11$ & LR & 5,0 & 2,5 & 1,5 \\
& DR $^{*}$ & 3,0 & 1,5 & 0,5 \\
$22 / 10 / 11$ & LR $^{*}$ & 4,5 & 1,0 & 1,5 \\
& DR $^{*}$ & 1,0 & 1,0 & 1,0 \\
$12 / 11 / 11$ & LR $^{*}$ & 0,0 & 0,0 & 0,0 \\
& DR $^{*}$ & 0,0 & 0,0 & 0,0 \\
$26 / 11 / 11$ & LR $^{*}$ & 3,5 & 1,5 & 1,0 \\
& DR $^{*}$ & 0,5 & 0,5 & 0,0 \\
\hline
\end{tabular}

${ }^{*}$ DR: Dalam Rumah

*LR: Luar Rumah

Tabel 6. Kepadatan relatif nyamuk Anopheles aconitus yang tertangkap dengan umpan orang pada malam hari bedasarkan jam penangkapan

\begin{tabular}{|c|c|c|}
\hline $\begin{array}{c}\text { Jam } \\
\text { Penangkapan }\end{array}$ & Di luar rumah & $\begin{array}{c}\text { Di dalam } \\
\text { rumah }\end{array}$ \\
\hline (WIB) & MHD & MHD \\
\hline $18.00-19.00$ & 0 & 0 \\
\hline $19.00-20.00$ & 0,25 & 0 \\
\hline $20.00-21.00$ & 0,25 & 0 \\
\hline $21.00-22.00$ & 0,5 & 0,25 \\
\hline $22.00-23.00$ & 0 & 0 \\
\hline $23.00-24.00$ & 0 & 0 \\
\hline $00.00-01.00$ & 0 & 0 \\
\hline $01.00-02.00$ & 0 & 0 \\
\hline $02.00-03.00$ & 0 & 0 \\
\hline $03.00-04.00$ & 0 & 0,125 \\
\hline $04.00-05.00$ & 0 & 0 \\
\hline $05.00-06.00$ & 0 & 0 \\
\hline Jumlah & 1 & 0,375 \\
\hline
\end{tabular}

Tabel 7. Kepadatan relatif nyamuk Anopheles sundaicus yang tertangkap dengan umpan orang pada malam hari bedasarkan jam penangkapan

\begin{tabular}{|c|c|c|}
\hline $\begin{array}{c}\text { Jam Penangkapan } \\
\text { (WIB) }\end{array}$ & Di luar rumah & $\begin{array}{c}\text { Di dalam } \\
\text { rumah }\end{array}$ \\
\hline & MHD & $\overline{\mathrm{M}} \mathrm{HD}$ \\
\hline $18.00-19.00$ & 0 & 0 \\
\hline $19.00-20.00$ & 0,375 & 0 \\
\hline $20.00-21.00$ & 0,25 & 0 \\
\hline $21.00-22.00$ & 0,125 & 0,125 \\
\hline $22.00-23.00$ & 0 & 0,25 \\
\hline $23.00-24.00$ & 0 & 0,25 \\
\hline $00.00-01.00$ & 0 & 0,125 \\
\hline $01.00-02.00$ & 0 & 0 \\
\hline $02.00-03.00$ & 0,125 & 0 \\
\hline $03.00-04.00$ & 0,125 & 0 \\
\hline $04.00-05.00$ & 0,25 & 0 \\
\hline $05.00-06.00$ & 0 & 0 \\
\hline Jumlah & 1,25 & $\overline{0}, 75$ \\
\hline
\end{tabular}

Pada Tabel 7 terlihat bahwa aktivitas mengigit nyamuk Anopheles sundaicus di luar rumah pada jam 19.00 s/d 22.00 dan jam 02.00 s/d 05.00 dengan waktu puncak jam 19.00 dan di dalam rumah pada jam 21.00 s.d 01.00.

Pada Tabel 8 terlihat bahwa aktivitas mengigit nyamuk Anopheles subpictus di luar rumah pada jam 19.00 s/d 01.00 dan pada jam 02.00 s/d 05.00 dengan waktu puncak pada jam $02.00 \mathrm{~s} / \mathrm{d}$ 03.00. Di dalam rumah aktivitas mengigit nyamuk pada jam $20.00 \mathrm{~s} / \mathrm{d}$ 01.00 dan jam $02.00 \mathrm{~s} / \mathrm{d} 04.00$ dengan waktu puncak pada jam $22.00 \mathrm{~s} / \mathrm{d} 23.00$. 
Tabel 8. Kepadatan relatif nyamuk Anopheles subpictus yang tertangkap dengan umpan orang pada malam hari bedasarkan jam penangkapan

\begin{tabular}{|c|c|c|}
\hline $\begin{array}{c}\text { Jam } \\
\text { Penangkapan }\end{array}$ & Di luar rumah & $\begin{array}{c}\text { Di dalam } \\
\text { rumah } \\
\end{array}$ \\
\hline (WIB) & MHD & MHD \\
\hline $18.00-19.00$ & 0 & 0 \\
\hline $19.00-20.00$ & 0,5 & 0 \\
\hline $20.00-21.00$ & 0,25 & 0,125 \\
\hline $21.00-22.00$ & 0,25 & 0,125 \\
\hline $22.00-23.00$ & 0,375 & 0,375 \\
\hline $23.00-24.00$ & 0,25 & 0,25 \\
\hline $00.00-01.00$ & 0,375 & 0,125 \\
\hline $01.00-02.00$ & 0 & 0 \\
\hline $02.00-03.00$ & 0,75 & 0,125 \\
\hline $03.00-04.00$ & 0,25 & 0,125 \\
\hline $04.00-05.00$ & 0,375 & 0 \\
\hline $05.00-06.00$ & 0 & 0 \\
\hline Jumlah & 3,375 & 1,25 \\
\hline
\end{tabular}

\section{PEMBAHASAN}

Penangkapan menggunakan light trap didapatkan lima spesies Anopheles: An.sundaicus, An.subpictus, An.barbitoris, An.kochi dan An.aconitus. Penangkapan menggunakan umpan orang baik di luar rumah dan di dalam rumah pada pagi hari dan malam hari didapatkan tiga spesies Anopheles: An.aconitus, An.sundaicus, dan An.subpictus.

Berdasarkan penelitian yang telah dilakukan dapat diketahui bahwa dari semua nyamuk Anopheles yang tertangkap, nyamuk An.subpictus dan An.sundaicus paling banyak ditemukan dengan persentase $(49,5 \%)$ dan $(29,4 \%)$. Hal ini membuktikan bahwa An.sundaicus dan An.subpictus memiliki kontribusi yang besar dalam penularan penyakit malaria. Menurut Suwito et al, banyaknya vektor berkorelasi positif dengan tingginya kasus penyakit. ${ }^{5}$

Dari penelitian ini didapatkan bahwa An.sundaicus, An.subpictus dan An.aconitus memiliki kecenderungan untuk mengigit di luar rumah (eksofagik). Hasil penelitian ini sama dengan penelitian sebelumnya bahwa An.sundaicus dan An.subpictus lebih suka mengigit di luar rumah (eksofagik). ${ }^{6}$ Begitu juga dengan penelitian sebelumnya mendapatkan bahwa nyamuk An.aconitus cenderung mengigit di luar rumah (eksofagik). ${ }^{7}$ Keadaan ini semakin meningkatkan resiko kejadian malaria jika penduduk suka keluar malam untuk berkumpul di warung ataupun bekerja lembur di malam hari seperti halnya para pekerja bangunan PLTU Teluk Sirih di Kecamatan Bungus. Risiko kejadian malaria akan semakin meningkat lagi jika keluar malam tanpa menggunakan pakaian pelindung seperti baju berlengan panjang, celana panjang dan repellent. $^{8}$

Berdasarkan identifikasi yang telah dilakukan pada nyamuk yang tertangkap di pagi hari dengan menggunakan aspirator, ditemukan An. aconitus yang hinggap istirahat di luar rumah sebanyak 3 ekor dan An.subpictus di dalam rumah sebanyak 2 ekor. Hal ini menunjukkan populasi nyamuk Anopheles menurun pada pagi hari dibandingkan pada malam hari. Nyamuk Anopheles merupakan serangga yang aktif mencari makan pada malam hari. Puncak gigitan nyamuk Anopheles di dalam rumah meningkat pada jam 23.00 WIB kemudian menurun dan meningkat lagi pada jam 02.00 dan 03.00 dini hari, sedangkan di luar rumah puncak gigitan meningkat pada jam 24.00 dan 05.00 dini hari. $^{9}$

Penelitian ini membuktikan bahwa aktivitas mengigit nyamuk An.aconitus dimulai pada jam 19.00 s/d 22.00 di luar rumah dan jam 21.00 s/d 22.00 dan $03.00 \mathrm{~s} / \mathrm{d} 04.00$ di dalam rumah. Puncak gigitan pada jam $21.00 \mathrm{~s} / \mathrm{d} 22.00$ baik di dalam maupun luar rumah. Hasil ini menunjukkan bahwa An.aconitus aktif menggigit manusia pada malam hari dan menurun aktivitasnya pada dini hari serta lebih cenderung mengigit di luar rumah (eksofagik). Hal tersebut sesuai dengan penelitian terdahulu di Propinsi Jawa Tengah menemukan puncak gigitan nyamuk An.aconitus pada jam $21.00 \mathrm{~s} / \mathrm{d} 24.00 \mathrm{WIB}^{10}$

Dari penangkapan nyamuk dengan menggunakan umpan orang didapatkan bahwa aktivitas mengigit nyamuk An.sundaicus dimulai pada 
jam 19.00 s/d 22.00 dan 02.00 s/d 05.00 di luar rumah dan pada jam $21.00 \mathrm{~s} / \mathrm{d}$ 01.00. Puncak gigitan nyamuk di luar rumah pada jam 19.00 s/d 20.00 sedangkan puncak gigitan di dalam rumah pada jam $22.00 \mathrm{~s} / \mathrm{d}$ 24.00. Hal ini sama dengan hasil penelitian sebelumnya menemukan aktivitas mengigit nyamuk An. sundaicus sepanjang malam dengan puncak gigitan di dalam rumah pada jam $23.00 \mathrm{~s} / \mathrm{d} 24.00 .^{11}$ Namun aktivitas puncak menggigit nyamuk Anopheles di luar rumah sedikit berbeda yaitu pada jam $02.00 \mathrm{~s} / \mathrm{d}$ 03.00 .

Aktivitas mengigit nyamuk An.subpictus di dalam rumah dimulai pada jam $20.00 \mathrm{~s} / \mathrm{d} 04.00$ dan di luar rumah pada jam $19.00 \mathrm{~s} / \mathrm{d}$ 05.00. aktivitas An.subpictus terjadi sepanjang malam dengan puncak gigitan pada jam $02.00 \mathrm{~s} / \mathrm{d} 03.00$ di luar rumah dan jam 22.00 s/d 23.00 di dalam rumah. Hasil yang serupa juga didapatkan oleh penelitian bioekologi nyamuk Anopheles di wilayah pantai timur Kabupaten Parigi Moutung Sulteng didapatkan aktivitas mengigit nyamuk Anpheles subpictus sepanjang malam dengan puncak gigitan di dalam rumah jam 22.00 s/d 24.00 dan jam $01.00 \mathrm{~s} / \mathrm{d}$ 02.00. Puncak gigitan nyamuk di luar rumah pada jam $21.00 \mathrm{~s} / \mathrm{d} 22.00$ dan meningkat kembali pada jam $02.00 \mathrm{~s} / \mathrm{d} 03.00 .^{12}$

Anopheles subpictus merupakan spesies Anopheles yang memiliki kepadatan tertinggi di daerah sekitar PLTU Teluk Sirih Kecamatan Bungus dengan aktivitas mengigit sepanjang malam, lebih cenderung eksofagik.

Desa Teluk Sirih merupakan suatu lahan baru yang digunakan untuk pembangunan PLTU, di sekitar daerah pembangunan PLTU Teluk Sirih banyak terdapat rumah non permanen sebagai tempat tinggal para buruh pekerja.

Kondisi dinding rumah terbuat dari papan dan tidak rapat memudahkan nyamuk untuk masuk ke dalam rumah, dan terdapatnya genangan air di sekitar rumah merupakan tempat perindukan bagi larva nyamuk, sehingga meningkatkan risiko kejadian malaria bagi para pekerja buruh serta penduduk sekitar pembangunan daerah PLTU Teluk Sirih Kecamatan Bungus Kota Padang.

Penderita malaria di daerah sekitar PLTU Teluk Sirih Kecamatan Bungus adalah buruh yang bekerja dalam pembangunan PLTU tersebut, besar kemungkinan para pekerja terpapar dengan vektor malaria ketika bekerja di malam hari dan tanpa menggunakan pelindung diri.

Sehingga dapat dikatakan bahwa nyamuk Anopheles subpictus paling potensial untuk menularkan malaria di daerah sekitar PLTU Teluk Sirih Kecamatan Bungus.

\section{KESIMPULAN}

Spesies Anopheles nyamuk tersangka vektor di daerah sekitar PLTU Teluk Sirih Kecamatan Bungus adalah An.Subpictus (49,5\%), An.Sundaicus (29,4\%), dan An.aconitus (14,7\%).

Kepadatan nyamuk Anopheles aconitus mengigit orang di luar rumah pada malam hari adalah 1 ekor/orang/malam, dan di dalam rumah adalah 0,375 ekor/orang/malam, Anopheles sundaicus di luar rumah pada malam hari adalah 1,25 ekor/orang/malam, dan Anopheles subpictus diluar rumah pada malam hari kepadatannya 3,375 ekor/orang/malam, dan di dalam rumah 1,125 ekor/orang/malam.

MBR di luar rumah didapatkan dua kali lipat dari di dalam rumah, sehingga nyamuk Anopheles sundaicus, Anopheles subpictus, dan Anopheles aconitus bersifat eksofagik.

\section{UCAPAN TERIMA KASIH}

Terima kasih kepada penduduk Teluk Sirih yang berada di sekitar PLTU Teluk Sirih dan segenap pekerja bangunan PLTU Teluk Sirih yang telah membantu penulis dalam menyelesaikan penelitian ini.

\section{DAFTAR PUSTAKA}

1. Harijanto, Paul N. Malaria. Dalam: IImu Penyakit Dalam Jilid III. Edisi ke-5. Jakarta: Interna Publishing; 2009.

2. Centers for Disease Control and Prevention. Malaria. (diunduh 16 April 2012). Tersedia dari: URL: HYPERLINK http://www.cdc.gov/malaria/ about/facts.html

3. Depkes RI. Pedoman penatalaksanaan kasus malaria di Indonesia. Jakarta: Depkes; 2008. 
4. Depkes RI. Epidemiologi malaria di Indonesia. Jakarta : Depkes; 2011

5. Suwito H, Kusumawati S, Sigit $H$, Supratman, Sukowati. Hubungan Iklim kepadatan nyamuk anopheles dan kejadian penyakit malaria. J Entomologi Indonesia. 2010;7(1):42-53.

6. Adrial. Fauna nyamuk anopheles vektor malaria di daerah sekitar kampus Universitas Andalas Limau Manih, Kodya Padang, Provinsi Sumatera Barat. (diunduh 22 Januari 2012). Tersedia dari: URL: HYPERLINK http://repository.unand.ac.id

7. Munif A. Dinamika populasi anopheles aconitus kaitannya dengan prevalemsi malaria di Kecamatan Cineam Tasikmalaya. Media Litbang Kesehatan. 2004;14(4):15-9.

8. Getas IW. Faktor resiko penularan penyakit malaria di sekitar Laguna Kecamatan Tanjung Kabupaten Lombok Utara. Media Bina IImiah 1. 2012;6(4):1-4.
9. Rosa E, Setyaningrum Endah, Murwani, Irwan $\mathrm{H}$. Identifikasi dan aktivitas menggigit nyamuk vektor malaria di daerah Pantai Puri Gading Kelurahan Suka Maju. (diunduh 20 Desember 2011). Tersedia dari: URL: HYPERLINK http://flemlit.unila.ac.id

10. Boesri H, Boewono, Tri Damar. Situasi malaria dan vektornya di Desa Giritengah dan Desa Giripurno Kecamatan Borobudur Kebupaten Magelang Jawa Tengah. J Ekologi Kesehatan. 2006;5(3):458-71.

11. Sukowati, Supratman, Shinta. Habitat perkembangbiakan dan aktivitas menggigit nyamuk anopheles Sundaicus dan anopheles Subpictus di Purworejo Jawa Tengah. J Ekologi Kesehatan. 2009;8(1):915-25.

12. Garjito T, Jastal, Yunus W, Lili, Siti C, Ahmad E, et al. Studi bioekologi nyamuk anopheles di wilayah Pantai Timur Kabupaten Parigi-Moutong Sulawesi Tengah. Buletin Penelitian Kesehatan. 2004;32(2). 49-61. 